\title{
Correspondence: Newer oral rehydration solution OS-1 for emesis gravidarum
}

\author{
Atsushi Imai", Kazutoshi Matsunami, Hiroshi Takagi, Satoshi Ichigo \\ Department of Obstetrics and Gynecology, Matsunami General Hospital, Gifu, Japan; \\ *Corresponding Author: aimai@matsunami-hsp.or.jp
}

Received 6 February 2012; revised 8 March 2012; accepted 10 April 2012

\begin{abstract}
Though nausea and vomiting are quite common in pregnancy, hyperemesis is found in only 1 - 2 patients per 100 . Appropriate oral fluid and electrolyte replacement is the initial treatment regimen for patients with mild to moderate emesis to avoid hyperemesis gravidarum defined as dehydration, electrolyte unbalance and ketosis. A newer oral rehydration solution OS-1 therapy may be safe and feasible in the mild to moderate emesis gravidarum population. Physicians are encouraged to use this practice to maintain the amount of water in the body and electrolytes and to improve the patient's comfort.
\end{abstract}

Keywords: Hyperemesis Gravidarum; Nausea and Vomiting During Pregnancy; Oral Rehydration

Solution; OS-1

\section{INTRODUCTION}

Hyperemesis gravidarum is a common problem for an obstetrician. Nausea and vomiting (mild to moderate emesis) are common symptoms in early pregnancy. In most cases, the condition is self-limiting and subsides by around 20 weeks gestation. However, in up to $20 \%$ of cases, nausea and vomiting may continue until delivery. When prolonged or severe, this is known as hyperemesis gravidarun, which can, in individual cases, be life threatening. The hyperemesis gravidarum is sufficiently pernicious acidosis from starvation, alkalosis from loss of hydrochloric acid in vomitus, and hypokalaemia [1]. An obviously dehydrated woman, with ketonuria greater than $2++$ on urinalysis unquestionably requires admission to hospital for intravenous rehydration and/or antiemetic therapy [2]. Lesser degrees of severity may benefit from other management options. Extreme cases may require nasogastric or parenteral nutrition.

The most important step is for the patient to drink enough fluids to avoid dehydration which exacerbates nausea [2]. Oral rehydration is most easily and quickly accomplished and this reduces adverse symptoms very effectively. If the woman is unable to tolerate oral fluids admission to hospital is mandatory. Electrolyte-replacement drinks and oral nutritional supplements are advisable for ensuring maintenance of electrolyte balance and an adequate intake of calories [3]. Protein-predominant meals have a positive effect because they are eupeptic and are able to reduce nausea more effectively than equicaloric carbohydrate and fat meals or noncaloric meals.

There are many publications on oral rehydration solution [4-6]. Among them, OS-1 (Otsuka Pharmaceutical Factory, Tokushima, Japan) is a new oral rehydration solution that contains a balanced concentration of carbohydrates and electrolytes based on the concept of oral rehydration therapy as recommended by WHO. The composition of OS-1 (Table 1) is based on the guidelines of the American Academy of Pediatrics (AAP), which has promoted the use of oral rehydration therapy. This is suitable for the provision and maintenance of water and electrolytes in cases of mild to moderate dehydration condition [7]. Specifically, OS-1 is suitable for dehydration associated with vomiting, diarrhea, and fever due to infectious enteritis and colds, as well as dehydration condition due to reduced food intake [7]. Based on these findings, OS-1 may also be sufficient to improve symptoms

Table 1. Ingredients of OS-1.

\begin{tabular}{ll}
\hline $\mathrm{Na}^{+}$ & $50 \mathrm{mmol} / \mathrm{L}$ \\
\hline $\mathrm{K}^{+}$ & $20 \mathrm{mmol} / \mathrm{L}$ \\
$\mathrm{Mg}^{2+}$ & $1 \mathrm{mmol} / \mathrm{L}$ \\
$\mathrm{Cl}^{-}$ & $50 \mathrm{mmol} / \mathrm{L}$ \\
Base & $18 \mathrm{mmol} / \mathrm{L}$ \\
Other anions & $4 \mathrm{mmol} / \mathrm{L}$ \\
Glucose & $1.8 \%$ \\
Carbohydrate & $2.5 \%$ \\
Calories & $100 \mathrm{kcal} / \mathrm{L}$ \\
\hline
\end{tabular}


(nausea and vomiting) during pregnancy because it may provide maintaining hydration or quick and sufficient rehydration. In our preliminary study of six patients who consumed $500 \mathrm{ml}$ of OS-1 during the morning, the condition was self limiting and subsided by around 15 weeks gestation (personal communication). Though experience in the management of emesis gravidarum with this oral rehydration solution is limited, OS-1 must be taken into consideration for avoiding hospitalization, medications, intravenous hydration and other stress.

\section{REFERENCES}

[1] Kuşcu, N. and Koyuncu, F. (2002) Hyperemesis gravidarum: Current concepts and management. Postgraduated Medical Journal, 78, 76-79. doi:10.1136/pmj.78.916.76

[2] Sheehan, P. (2007) Hyperemesis gravidarum-Assessment and management. Australian Family Physician, 36, 698-701.

[3] Jueckstock, J., Kaestner, R. and Mylonas, I. (2010) Managing hyperemesis gravidarum: A multimodal challenge.
BMC Medicine, 8, 46-57. doi:10.1186/1741-7015-8-46

[4] Alves, J., Troster, E. and de Oliveira, C. (2011) Isotonic saline solution as maintenance intravenous fluid therapy to prevent acquired hyponatremia in hospitalized children. Journal of Pediatrics, 87, 476-486.

[5] Itou, K., Fukuyama, T., Sasabuchi, Y., Yasuda, H., Suzuki, N., Hinenoya, H., Kim, C., Sanui, M., Taniguchi, H., Miyao, H., Seo, N., Takeuchi, M., Iwao, Y., Sakamoto, A., Fujita, Y. and Suzuki, T. (2012) Safety and efficacy of oral rehydration therapy until $2 \mathrm{~h}$ before surgery: A multicenter randomized controlled trial. Journal of Anesthesiology, 26, 20-27.

[6] Mizzi, A., Tran, T., Karlnoski, R., Anderson, A., Mangar, D. and Camporesi, E. (2011) Voluven, a new colloid solution. Anesthesiology Clinic, 29, 547-555. doi:10.1016/j.anclin.2011.05.012

[7] Sakurai, Y., Uchida, M., Aiba, J., Mimura, F. and Yamaguchi, M. (2011) Safe practice of oral rehydration therapy by oral rehydration solution and carbohydrate loadingEvaluation by non-invasive gastric echo examination (Japanese Review). Masui, 60, 790-798. 